\title{
Glossário Hipertextual Colaborativo LV
}

\author{
Maria Jucilene Freire Lopes Marinho - jucilenef@gmail.com - UECE \\ Joana Laysa Lima Cunha - laysacunha@ gmail.com - IFCE \\ Alexandra Joca Gonçalves - ajg.virtual@gmail.com - SEDUC/CE \\ Gilvandenys Leite Sales - denyssales@gmail.com - IFCE
}

\begin{abstract}
Resumo: Este artigo apresenta a aplicação de uma métrica não-linear de avaliação à ferramenta Glossário do Moodle a ser utilizada durante o processo avaliativo das definições e comentários produzidos com o uso de mídias digitais. Como fuga a avaliação tradicional, aplicou-se o Modelo LV, uma metodologia e instrumento permissor de uma avaliação processual, formativa e reguladora de aprendizagens o qual se utiliza de parâmetros quali-quantitativos e de instrumentos e signos apoiados em linguagem iconográfica associada à menções qualitativas. $\mathrm{O}$ resultado foi a concepção da ferramenta Glossário Hipertextual Colaborativo LV, ou Glossário LV, o qual foi planejado a partir de estudos numa disciplina na modalidade blended-learning, apresentando uma ampla aceitação.
\end{abstract}

Palavras-Chave: ambiente virtual de aprendizagem, educação a distância, avaliação formativa, modelo LV, glossário LV

\section{Collaborative Hipertextual LV Glossary}

Abstract: This article presents an application of a nonlinear metric evaluation to the Glossary from Moodle to be applied over the evaluation process of definitions and comments produced using digital media. For the avoidance of the traditional evaluation system, the LV Model was applied, a methodology and instrument that can permit a procedural and formative evaluation, which is a learning regulator that uses qualitative and quantitative parameters and instruments and signs supported by an iconographic language associated with qualitative mentions. The result was the conception of the Collaborative Hipertextual LV Glossary, or LV Glossary, which was planned from studies on a blended-learning subject, presenting a wide acceptance.

Key-Words: learning management system, distance education, formative assessment, LV model, LV glossary

\section{INTRODUÇÃO}

O avanço das Tecnologias Digitais da Informação e Comunicação (TDIC) tem mudado nosso modo de viver, alterando a forma de trabalho e de convívio, além de incorporar novos costumes e tipos de comunicação, inclusive modificando as metodologias de ensino e de aprendizagem (FONSECA, 2015).

A Educação a Distância $(\mathrm{EaD})$ é uma modalidade de ensino representada pela interação entre Professor/Tutor-Aluno e Aluno-Aluno suportados pelas TDIC, as quais proveem espaços comuns ou lógicos, utilizando-se de recursos instrucionais e tecnológicos básicos, tais como, Internet, MP3, Vídeos, Animações, Redes Sociais, 
Fóruns, Chats, Ambientes Virtuais de Aprendizagem, dentre outros (MOORE e KEARSLEY, 2008, p. 26), possibilitando acesso amplo à instrução.

Como principais vantagens desta, Fonseca (2015) destaca a alta disponibilidade, a flexibilidade, representada pela permanência do estudante em seu ambiente cultural, profissional e familiar, a eficácia, que abrange o acesso a conteúdos instrucionais, utilização de recursos multimídias e comunicação bilateral frequente com seu Professor/Tutor e a formação de um aluno ativo.

Apesar dos benefícios propiciados pela $\mathrm{EaD}$, a mesma ainda enfrenta muitos desafios no que concerne a aceitação e adaptação à metodologia de ensino aplicada, ocasionando o aumento da taxa de evasão. É importante ressaltar que existe uma necessidade de disponibilização de suporte e auxílio para os alunos online, tendo em vista que é necessário estimular a descoberta e a construção do conhecimento. Fonseca (2015, p.18-19) afirma que "Temos de ofertar ricos ambientes de aprendizagem onde o aluno livremente possa navegar e aprofundar seu conhecimento de acordo com o seu desejo e da utilidade que atribui a conhecimento".

O ambiente virtual Moodle pode ser referenciado como exemplo de sala de aula virtual capaz de oferecer variados recursos que possam promover a construção do conhecimento, dentre eles destaca-se o Glossário, pois segundo Correia (2009 p. 31) este "é uma lista restrita de vocábulos de um determinado domínio do conhecimento, de um determinado registro linguístico, específicos da obra de um autor, etc.".

Em sua essência, o glossário envolve elementos puramente textuais, tendo por finalidade auxiliar ao usuário na compreensão de termos específicos de um determinado campo de estudo.

Como fuga a um modelo de glossário essencialmente textual, propõe-se a concepção de um modelo associado a elementos hipertextuais e mídias, que possa ser avaliado através de modelos formativos e, assim, promover uma experiência enriquecedora, possibilitando uma navegação livre entre termos na sala de aula virtual.

Portanto, busca-se verificar se a elaboração de um Glossário Hipertextualizado que permita a permanente mediação do Professor/Tutor, por meio de linguagem iconográfica e uso de menções qualitativas reguladoras de aprendizagem no processo de avaliação, contribui para a motivação e valorização dessa ferramenta como veículo de suporte à aprendizagem.

Para tanto, por apresentar essas características, além do uso de hipertextos, foram escolhidos para dar robustez a este trabalho, o modelo de avaliação formativa Learning Vectors (Modelo LV) e seus Vetores-Aprendizagem (SALES, 2010).

Esse artigo está organizado da seguinte forma: na seção a seguir trata-se da Aprendizagem Colaborativa trabalhada pelo uso de hipertextos, abrangendo até seu processo avaliativo. Na terceira parte a concepção do Glossário LV. E, por fim, uma apreciação e discussão dos resultados, seguido das considerações finais.

\section{COLABORAÇÃO, APRENDIZAGEM E AVALIAÇÃO EM EaD}

As formas de comunicação, seja oral ou escrita, representam a escolha entre a melhor ou mais adequada forma de interagir. A oralidade foi a principal forma de comunicação que se aproveitou de signos audíveis comuns para interação e compartilhamento de saberes.

Em contraposto com as sociedades orais, na sociedade escrita torna-se fundamental a compreensão do conteúdo exposto - símbolos escritos ou impressos. Ressalta-se como resultado da escrita, o texto, que "[...] tem uma incompletude, lacunas, 
é um recorte que se liga a outros textos; é um dos retalhos da colcha de pensamentos compostos por outros tecidos e com configuração peculiar" (PALANGE, 2012, p.2). Este, por sua vez, torna-se cada vez mais fundamental nos âmbitos educacional e lúdico.

No que concerne à evolução da educação, novas modalidades de apresentação de textos permitiram a transição do texto físico para o texto lógico, ou seja, os materiais impressos passam a ser processados e transformados em informação digital. Esta última apresenta-se de forma dinâmica, possibilitando uma nova forma de acessar os textos: o hipertexto, definido por Santaella (2008, p.47), por:

[...] vínculos não-lineares entre fragmentos textuais associativos, interligados por conexões conceituais (campos), indicativas (chaves) ou por metáforas visuais (ícones) que remetem, ao clicar de um botão, de um percurso de leitura a outro, em qualquer ponto da informação ou para diversas mensagens, em cascatas simultâneas de interconectadas.

Com o surgimento do hipertexto, é possível se aprender em várias situações. $\mathrm{O}$ paradigma de que só se ensina em sala de aula foi quebrado. Esta pode ser considerada uma mídia, dentre as diversas possíveis no conceito de Educação a Distância, podendo trabalhar com a internet, vídeos, sistemas operacionais, glossários online, dentre outros.

Portanto, considera-se relevante a utilização do glossário associado a hipertextos no intuito de dinamizar o recurso e, consequentemente potencializar a ferramenta, impactando assim na aprendizagem, convergindo para uma linguagem digital permitida pela hipertextualização, apresentando-se, na contemporaneidade, como natural e intrínseca.

Assim, a fim de intensificar essa associação, propõe-se a construção de um glossário hipertextual colaborativo visando promover interação, fortalecer as relações entre docentes e aprofundar o conhecimento. Pois, afirma Palloff e Pratt (2001, p.46) que a colaboração "é um processo que ajuda os alunos a atingir níveis mais produtivos de geração de conhecimento por meio da criação de objetivos comuns, trabalho conjunto e um processo compartilhado de construção de sentido".

E, como postula Schlemmer (2005, p.34) prover "espaços nos quais os sujeitos podem interagir e construir conhecimento" como é possibilitado pelo cenário de construção colaborativo através da ferramenta Glossário do AVA Moodle.

No que concerne à construção do conhecimento pela utilização do Glossário Hipertextual Colaborativo, faz-se necessário, sobretudo, discorrer sobre o processo avaliativo. Processo este com propósito de orientar o aluno tornando-o responsável por sua aprendizagem.

Assim, "a avaliação da aprendizagem necessita, para cumprir o seu verdadeiro significado, assumir a função de subsidiar a construção da aprendizagem bem-sucedida" (LUCKESI, 2006, p. 166), ou seja, assumir sua função formativa.

Para a aplicação de um modelo formativo na avaliação em $\mathrm{EaD}$, se faz necessário a presença virtual, um feedback frequente e promovedor de novas assimilações, suportados pelas TDIC como cenário lógico proporcionador da sensação de "estar junto virtual" (VALENTE, 2000).

Segundo Sales et al. (2012), "a não mudança na postura do Professor/Tutor pode gerar: abandono virtual, desmotivação e até mesmo a desistência do aprendiz de um curso em EaD online, o que implica em aumento dos índices de evasão”.

Adequa-se ao modelo virtual de aprendizagem um modelo formativo de avaliação, pois, segundo Haydt (2008), a mesma tem por função constatar o alcance dos objetivos e permitir o aperfeiçoamento do processo de ensino e aprendizagem durante todo o período letivo. 
Neste caso, o professor pode aproveitar-se das ferramentas da linguagem escrita, iconográfica, dentre outras, para obtenção de êxito na aprendizagem dos alunos.

Para isto, pode-se utilizar a ferramenta Glossário do AVA Moodle associada a elementos hipertextuais e mídias digitais com o intuito de promover uma construção coletiva de termos e conceitos pertinentes a determinado conteúdo.

\section{CONCEPÇÃo dO GLOSSÁRIO LV}

Para a concepção do Glossário Hipertextual Colaborativo LV, ou Glossário LV, utilizou-se da especificação matemática do Modelo LV aplicado ao Fórum LV.

A proposta deve-se pelo Modelo Learning Vectors, ou Modelo LV (SALES, 2010; SALES et al., 2008), apresentar uma metodologia formativa de avaliação nãolinear, e assim, considerar o além do quantitativo, a subjetividade inerente as postagens, ou seja, o caráter qualitativo das mesmas.

Para Sales et al. (2011) é característica desta ferramenta:

Fornecer feedbacks em tempo mínimo, suprindo a necessidade constante do Aluno/Aprendiz em acompanhar e verificar seu desempenho no curso; Reduzir a sobrecarga de trabalho gerada para o Professor/Tutor; Alertar quanto a evasão, face ser um instrumento que faz o controle de frequência; Ser instrumento de gerenciamento de notas e controle acadêmico por parte da instituição de ensino.

Este modelo utiliza um sistema de Vetores-Aprendizagem (Figura 1) para avaliar além de fóruns, atividades, chats e wikis, com o objetivo de facilitar a avaliação para o Professor/Tutor e, a visualização do resultado pelos alunos em cursos a distância, ou na modalidade blended-learning, ou B-learning.

Figura 1 - Representação Gráfica do Vetor-Aprendizagem
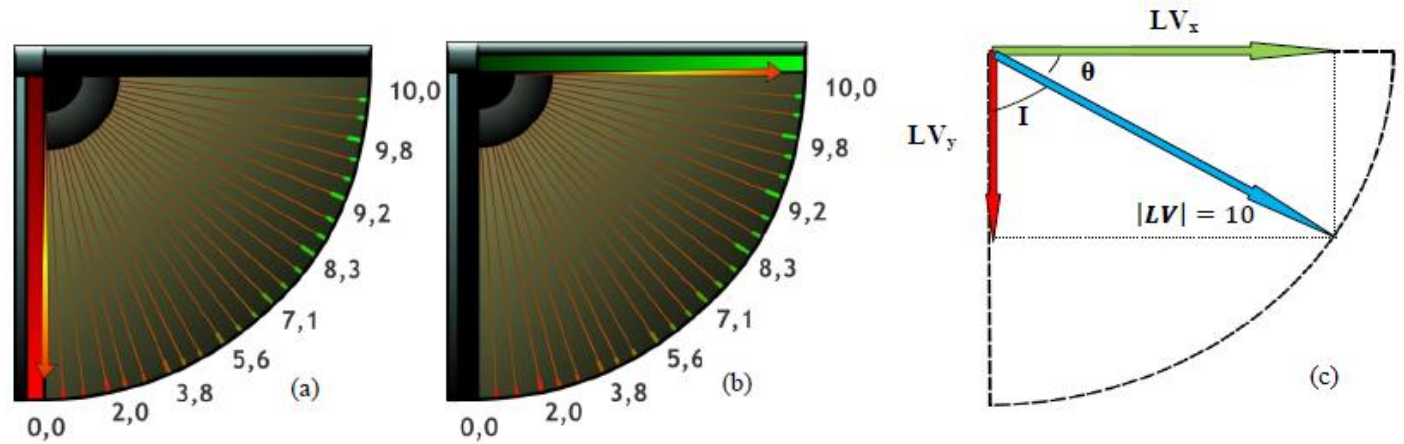

Fonte: Sales (2010)

A facilitação da avaliação do Professor/Tutor é realizada pela utilização de uma linguagem iconográfica (Coeficiente do Passo - CP), e suas menções associadas (Tabela 1), como reflexo da avaliação do Professor/Tutor diante das $n$ interações efetivadas.

Tabela 1 - LV Ícones e respectivas menções qualitativas

\begin{tabular}{|c|c|c|c|c|c|c|}
\hline LV Ícones & $\odot$ & $\odot$ & $\odot$ & $\odot$ & $\Theta$ & $\Theta$ \\
\hline CP & $\mathbf{4}$ & $\mathbf{3}$ & $\mathbf{2}$ & $\mathbf{1}$ & $\mathbf{0}$ & - \\
\hline Menções & Muito Bom & Bom & Regular & Fraco & Não Satisfatório & Neutro \\
\hline
\end{tabular}

Fonte: SALES (2010) 
O Vetor-Aprendizagem apresenta uma posição inicial $\theta=-90^{\circ}$ com a horizontal, representando a nota mínima (Figura 1 a), e pode deslocar-se, em sentido anti-horário, até $\theta=0^{\circ}$, representando a nota máxima (Figura $1 \mathrm{~b}$ ). A representação geométrica destes (Figura $1 \mathrm{c}$ ) inclui os componentes horizontal e vertical, respectivamente, representadas por $L_{\mathrm{x}}$ e $\mathrm{LV}_{\mathrm{y}}$, relacionando-se a positividade (eixo x) ou negatividade (eixo y) de desempenho do aluno.

$\mathrm{O}$ módulo do componente horizontal do $\mathrm{LV}\left(\mathrm{LV}_{\mathrm{x}}\right)$ implica diretamente no rendimento e situação final do aluno, sendo a nota final $\left(\mathrm{N}_{\mathrm{G}}\right)$ expressa pela Equação 1:

$$
N_{G}=L V_{x}=10 * \cos (-12 \alpha+I)
$$

Onde:

- $\alpha=7,5^{\circ}$ é o passo padrão de aprendizagem;

- I = Variação Angular Total.

O Glossário LV foi configurado para duas interações mínimas, dadas por uma definição (D) e um comentário (C). A equação de contabilização da variação angular $\mathrm{I}_{\mathrm{n}}$ é calculada pela Equação 2:

$$
I_{n}=\left\{\begin{array}{c}
3 C P \alpha / 2+I_{n-1} ; \text { para } n=1 \text { e } n=2 \\
-1 \alpha+I_{n-1} ; \text { para } n \geq 3 ; \text { se } C P=0 \text { ou } 1 ; \\
+1 \alpha+I_{n-1} ; \text { para } n \geq 3 ; \text { se } C P=2 ; 3 \text { ou } 4 ;
\end{array}\right.
$$

As interações podem ser classificadas mediante os seguintes critérios:

- D1 - primeira definição $(n=1)$. Primeira interação, inserção de definição à escolha do aluno, de acordo com o tema proposto.

- C1 - primeiro comentário $(n=2)$. Segunda interação, comentário realizado pelo aluno nas definições dos demais colegas.

- $\mathrm{D}_{\mathrm{n}>1}$ ou $\mathrm{C}_{\mathrm{n}>1}=$ demais interações. A partir da terceira interação $(\mathrm{n} \geq 3)$ podem ser efetuadas novas definições ou novos comentários.

Dessa forma, a variável I, em função de $\alpha$, pode assumir 25 possíveis valores representativos da nota do aluno (Tabela 2).

Tabela 2 - Variações Angulares e suas notas correspondentes

\begin{tabular}{|c|c|c|c|c|c|c|c|c|c|}
\hline$I$ & Nota & $I$ & Nota & $I$ & Nota & $I$ & Nota & $I$ & Nota \\
\hline $0 \alpha$ & 0,00 & $2,5 \alpha$ & 3,21 & $5 \alpha$ & 6,09 & $7,5 \alpha$ & 8,31 & $10 \alpha$ & 9,66 \\
\hline $0,5 \alpha$ & 0,70 & $3 \alpha$ & 3,83 & $5,5 \alpha$ & 6,59 & $8 \alpha$ & 8,66 & $10,5 \alpha$ & 9,81 \\
\hline $1 \alpha$ & 1,31 & $3,5 \alpha$ & 4,42 & $6 \alpha$ & 7,07 & $8,5 \alpha$ & 8,97 & $11 \alpha$ & 9,91 \\
\hline $1,5 \alpha$ & 1,95 & $4 \alpha$ & 5,00 & $6,5 \alpha$ & 7,52 & $9 \alpha$ & 9,24 & $11,5 \alpha$ & 9,98 \\
\hline $2 \alpha$ & 2,59 & $4,5 \alpha$ & 5,56 & $7 \alpha$ & 7,93 & $9,5 \alpha$ & 9,47 & $12 \alpha$ & 10,0 \\
\hline
\end{tabular}

O componente vertical, denominado $L_{\mathrm{y}}$ (Figura $1 \mathrm{c}$ ), que representa a negatividade de desempenho, é dado pela Equação 3:

$$
L V_{y}=10 * \operatorname{sen}(-12 \alpha+I)
$$


Logo, a relação entre os fatores positividade/negatividade $(\mathrm{P} / \mathrm{N})$ configura a métrica pedagógica não-linear denominada Fator $\beta$ (SALES, 2010), que se associa à característica qualitativa do modelo de avaliação LV. Este permite apontar o nível de desempenho do aluno no curso online, e pode ser obtido através da Equação 4:

$$
\beta=\frac{\text { Positividade }}{\text { Negatividade }}=\frac{\mathrm{P}}{\mathrm{N}}=\frac{\mathrm{LV} \mathrm{x}+3 * \Delta_{\mathrm{azul}}+2 * \Delta_{\text {verde }}+1 * \Delta_{\text {amarelo }}}{\mathrm{NTF}+\mathrm{LV} V_{\mathrm{y}}+2 * \Delta_{\text {vermelho }}+1{ }^{*} \Delta_{\text {laranja }}}
$$

Onde:

- $\Delta_{\text {azul }}, \Delta_{\text {verde }}$ e $\Delta_{\text {amarelo }} \Delta_{\text {vermelho }}$ e $\Delta_{\text {laranja }}$ representam a quantidade de LV Ícones Azul, Verde, Amarelo, Vermelho e Laranja, atribuídos, respectivamente.

- NTF (Número Total de Faltas).

O fator $\beta$ determina o desempenho (Tabela 3) do aluno, proporcionando um conceito diferenciado a não tradicional de avaliação.

\section{Tabela 3 - Escala de Desempenho e Intervalos do Fator $\beta$}

\begin{tabular}{|c|c|}
\hline Fator $\beta$ & $\begin{array}{c}\text { Escala de } \\
\text { Desempenho }\end{array}$ \\
\hline Muito Alto & $\beta \geq 3,78$ \\
\hline Alto & $2,62 \leq \beta \leq 3,78$ \\
\hline Médio & $0,90 \leq \beta \leq 2,62$ \\
\hline Baixo & $0,30 \leq \beta \leq 0,90$ \\
\hline Muito Baixo & $0 \leq \beta \leq 0,30$ \\
\hline
\end{tabular}

A especificação demonstrada foi aplicada ao Glossário LV, em uma situação real de uso, para validar a consistência do mesmo e verificar se esta proposta é capaz de, na prática, promover auxílio da aprendizagem. A seguir apresentam-se os resultados desta aplicação.

\section{APRESENTAÇÃO E DISCUSSÃO DOS RESULTADOS}

Um estudo de caso foi realizado utilizando-se blended-learning numa turma do oitavo semestre do curso técnico de Eletrotécnica do Instituto Federal de Educação, Ciência e Tecnologia do Ceará (IFCE). Para tanto, o ambiente Moodle Help Class Online foi utilizado como suporte a esta disciplina durante o segundo semestre letivo do ano de 2015, atendendo um público alvo de 21 (vinte e um) alunos.

Para a avaliação das participações foram considerados a relação com o tema proposto, o poder de síntese, a utilização de hipertextos e mídias associativas, a relevância dos comentários e a utilização adequada das referências. Tais parâmetros foram esclarecidos no contrato didático, juntamente com a proposta da atividade.

A totalidade dos alunos inscritos, ou $100 \%$, participou ativamente inserindo definições e apenas 18 estudantes, ou 85,7\%, comentaram nas interações dos demais (Gráfico 1). Observou-se que $90 \%$ dos alunos obtiveram um rendimento igual ou superior da média $(7,0)$ proposta pela instituição.

Com a finalidade de ilustrar a aplicação do Glossário LV, elaborou-se uma comparação entre o desempenho de dois alunos (Tabela 4), selecionados sob os 
seguintes critérios: mesma quantidade de postagens efetivadas e um aluno alcançando resultado satisfatório e outro, não, respectivamente, Alunos (a) e (b).

Tabela 4 - Desempenho dos Alunos (a) e (b)

\begin{tabular}{|c|c|c|c|c|c|c|c|c|}
\hline & $\mathrm{n}$ & Tipo & CP & $\alpha$ & Nota & $\mathbf{L} \mathbf{V}_{\mathbf{x}}$ & $\mathbf{L} \mathbf{V}_{\mathbf{y}}$ & $\beta$ \\
\hline \multirow{2}{*}{$\begin{array}{c}\text { Aluno } \\
\text { (a) }\end{array}$} & $1^{\mathrm{a}}$ & $\mathrm{D}$ & $\Theta_{4}$ & $6 \alpha$ & 7,07 & \multirow{2}{*}{9,24} & \multirow{2}{*}{$\mathbf{3 , 8 3}$} & \multirow{2}{*}{3,72} \\
\hline & $2^{\mathrm{a}}$ & $\mathrm{C}$ & (.) 2 & $+3 \alpha=9 \alpha$ & 9,24 & & & \\
\hline \multirow{2}{*}{$\begin{array}{l}\text { Aluno } \\
\text { (b) }\end{array}$} & $1^{\mathrm{a}}$ & $\mathrm{D}$ & (.) 3 & $4,5 \alpha$ & 5,56 & \multirow{2}{*}{6,59} & \multirow{2}{*}{7,52} & \multirow{2}{*}{1,28} \\
\hline & $2^{a}$ & $\mathrm{D}$ & (.) 2 & $+1 \alpha=5,5 \alpha$ & 6,59 & & & \\
\hline
\end{tabular}

Fonte: Elaborado pelos autores

Vale salientar que o Aluno (a) perfez as orientações (ao inserir pelo menos uma definição e um comentário), mas, em virtude do comentário ter recebido avaliação Regular nesta, o mesmo não obteve nota máxima. O Aluno (b), mesmo realizando duas interações, não cumpriu as exigências mínimas ao postar apenas duas definições e nenhum comentário, em consequência disso não obteve rendimento satisfatório.

Com a finalidade de demonstrar o grau de satisfação e concordância dos envolvidos, foi aplicado uma Pesquisa categorizada segundo o acesso e usabilidade, feedback e avaliação do Professor/Tutor e relevância do Glossário LV.

Quanto à clareza das instruções e a facilidade de acesso e associação de termos do Glossário LV, os alunos oscilam na escala entre a concordância e a forte concordância, enquanto apenas $10 \%$ destes concordaram parcialmente nos itens citados (Gráfico 1).

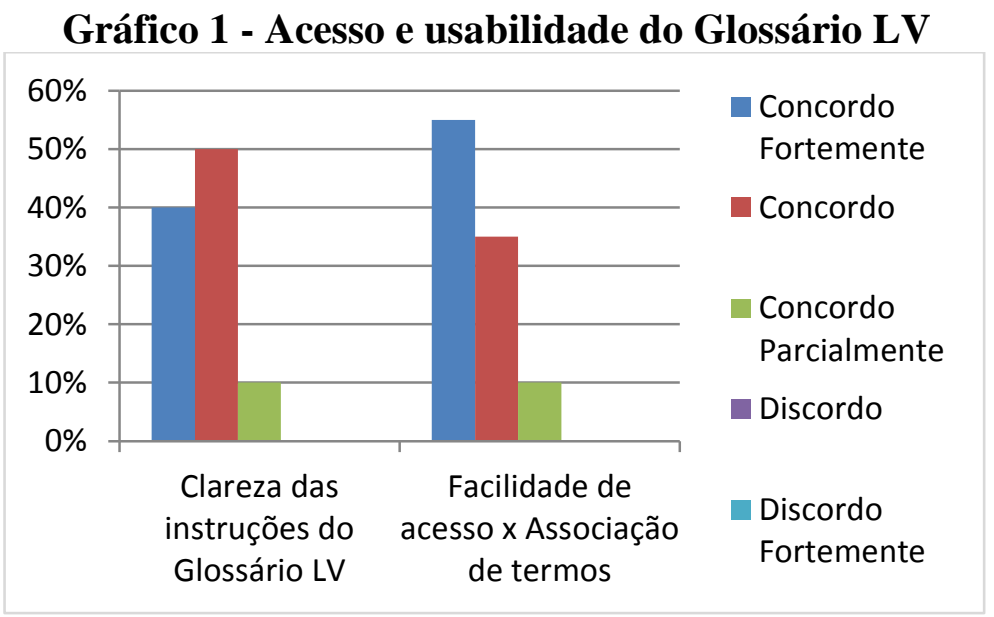

Fonte: Elaborado pelos autores

Os alunos oscilam na escala entre a concordância parcial e a forte concordância quanto a atuação do Professor/Tutor e a clareza das menções qualitativas. No que diz respeito à utilização de LV Ícones no Glossário LV, 10\% dos discentes discordaram enquanto os demais se dividiram entre parcialidade e plena concordância (Gráfico 2).

\section{Gráfico 2 - Feedback e avaliação do Professor/Tutor}




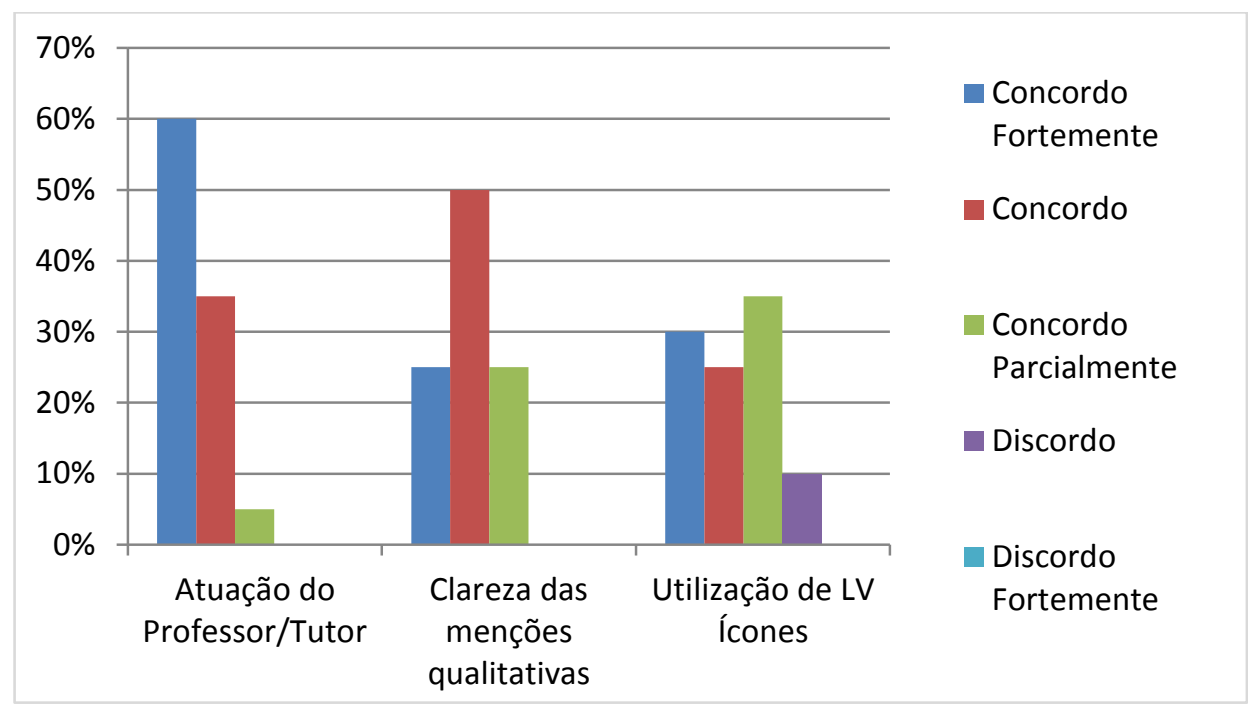

Fonte: Elaborado pelos autores

Houve uma oscilação por parte dos alunos na escala entre a concordância parcial e a forte concordância quanto à relevância e o trabalho colaborativo do Glossário LV. No que diz respeito à importância do Glossário LV na composição da média, $10 \%$ dos discentes discordaram, enquanto os demais se distribuíram em quantidades aproximadas entre parcialidade e plena concordância (Gráfico 3).

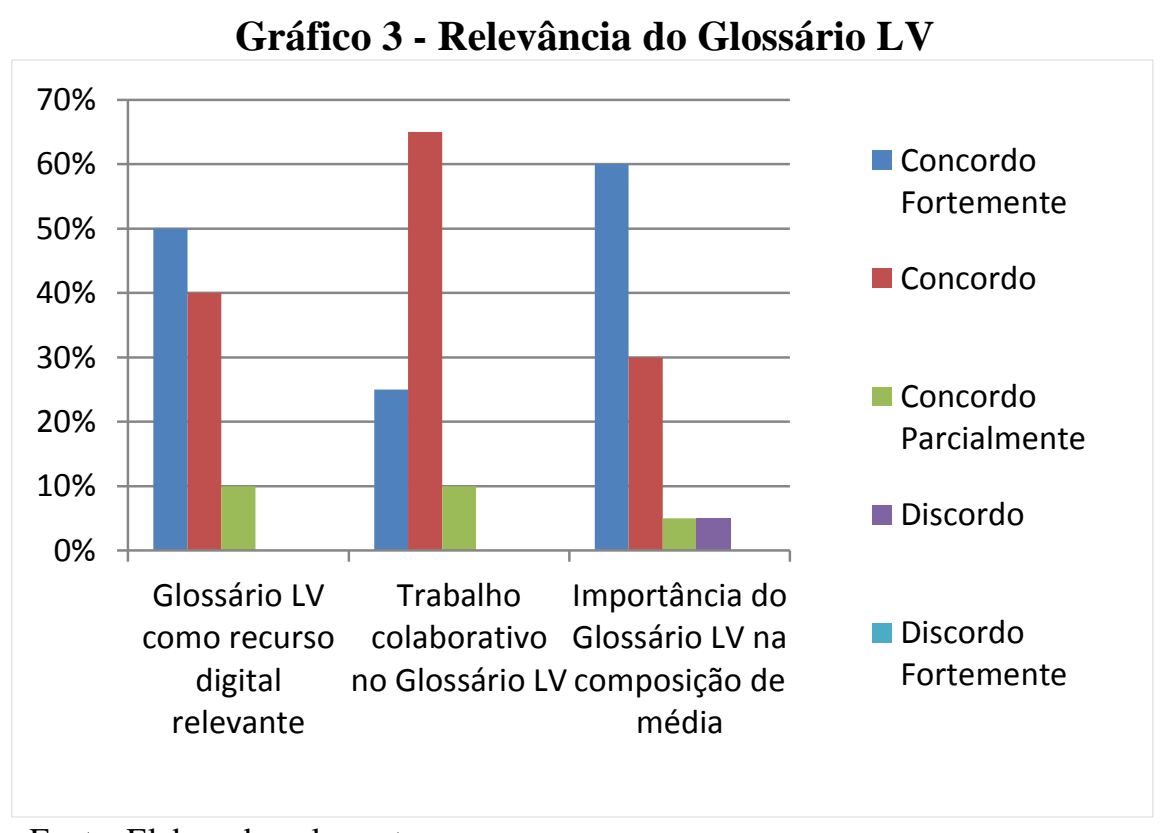

Fonte: Elaborado pelos autores

Houve, de forma generalizada, uma alternância entre satisfação parcial e total dos estudantes em relação à construção do Glossário LV (Gráfico 4).

\section{Gráfico 4 - Satisfação quanto ao Glossário LV}




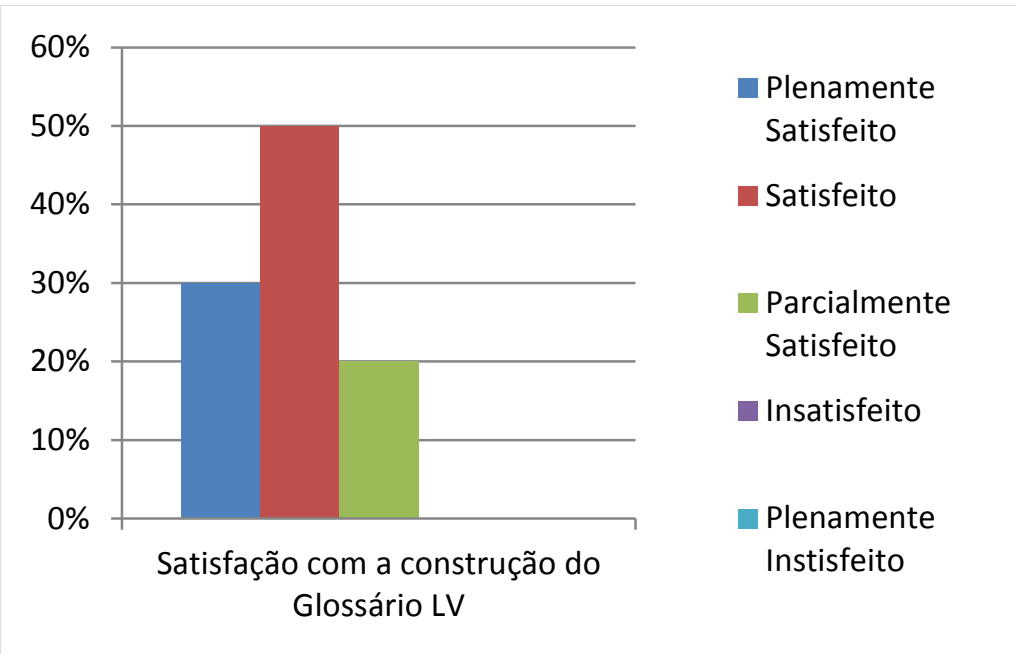

Fonte: Elaborado pelos autores

Abordam-se, a seguir, as considerações finais.

\section{CONSIDERAÇÕES FINAIS}

O objetivo desta pesquisa foi contribuir, embasado em um modelo formativo e não linear de avaliação, com a ferramenta Glossário do AVA Moodle. Esta colaboração efetuou-se pela aplicação das métricas não-lineares e do Vetor-Aprendizagem do Modelo LV, concebendo assim, o Glossário Hipertextual Colaborativo LV, ou Glossário LV.

A aplicação do Modelo LV deve-se à sua capacidade em assistir aspectos qualitativos emitidos através das subjetividades nas colocações dos participantes, subsidiando assim um processo de avaliação formativo não linear.

Além de proporcionar uma avaliação diferenciada, buscou-se também, tornar esta a ferramenta relevante na educação contemporânea para a aprendizagem. Logo, associou-se, a utilização de links e diversos tipos de mídias, tais como, imagens, vídeos, dentre outras, com o propósito de hipertextualizá-la, ampliando acessos.

Com a finalidade de verificar a pertinência do modelo concebido, o mesmo foi aplicado em um Estudo de Caso na disciplina de Física VI de uma turma presencial de oitavo semestre do curso técnico de Eletrotécnica do Instituto Federal de Educação, Ciência e Tecnologia do Ceará (IFCE).

Os resultados desta aplicação apontam a importância do Glossário LV como suporte a aprendizagem colaborativa, permitindo uma ágil associação de termos e respectivos conceitos e a pertinência do uso de menções qualitativas refletindo de forma clara a avaliação do Professor/Tutor. Para o aluno, a ferramenta oferece, como retorno, feedback com caráter avaliativo e orientador, podendo ou não inferir novas interações com melhor qualidade.

Assim, a pesquisa foi elucidada ao se demonstrar a possibilidade de desenvolver uma metodologia de construção e avaliação da ferramenta assíncrona Glossário do AVA Moodle, com o objetivo de prover suporte ao aprendizado e estímulo ao permanente acompanhamento do curso em EaD.

Contudo, ressalta-se o alto grau de satisfação de seus usuários com a utilização do Glossário LV, verificado pela pesquisa de satisfação, a qual corroborou com a hipótese levantada inicialmente de que a elaboração de um Glossário Hipertextualizado 
com a permanente mediação do Professor/Tutor por meio de linguagem iconográfica e uso de menções qualitativas contribui para a motivação e valorização dessa ferramenta como veículo de suporte à aprendizagem.

Por fim, um modelo de avaliação não-linear, que valorize aspectos qualiquantitativos possibilitando a formação de um aluno ativo, promoveu uma construção reguladora do conhecimento funcionando como um aporte ao processo de avaliação formativa em $\mathrm{EaD}$ online.

Como perspectivas futuras de pesquisa pode-se sugerir a aplicação desta metodologia em um curso totalmente a distância, além da modalidade blended-learning aqui apresentada, AVA e a possibilidade da avaliação por pares.

\section{REFERÊNCIAS}

CORREIA, Margarita. Os dicionários portugueses. Lisboa: ILTEC/Editorial Caminho, 2009.

FONSECA, João José Saraiva da. Educação a Distância: Um conceito a erradicar. Sobral: Egus, 2015.

HAYDT. Regina C. Avaliação do Processo de Ensino-Aprendizagem. 6ed. São Paulo: Editora Ática, 2008.

LUCKESI, C. C. Avaliação da aprendizagem escolar: estudos e proposições. São Paulo: Cortez Editora, 2006.

MOORE, M. G.; KEARSLEY, G. Educação a distância: uma visão integrada. Tadução Roberto Galman. São Paulo: Cengage Learning, 2008

PALANGE, Ivete. Texto, hipertexto, hipermídia: uma metamorfose ambulante. Boletim Técnico do Senac, Rio de Janeiro, v. 38, n. 1, p.61-73, jan/abr 2012. Disponível em: <http://www.senac.br/media/6628/artigo6.pdf>. Acesso em: 12/04/2016.

PALLOFF, Rena M.; PRATT, Keith. O Aluno Virtual: Um Guia para Trabalhar com Estudantes On-line. Porto Alegre: Artmed, 2007. Tradução de: Viniciues Figueira.

SALES, Gilvandenys Leite, Barroso, G. C., Soares, J. M. Learning Vectors (LVs) um Instrumento Automatizado de Avaliação para Suporte a Aprendizagem em EaD.. RENOTE. Revista Novas Tecnologias na Educação, v.6, p.37, 2008.

SALES, G. L; Learning Vectors (LV): um modelo de avaliação da aprendizagem em $\mathrm{EaD}$ online aplicando métricas não-lineares. Tese (Doutorado) - Universidade Federal do Ceará, Curso de Pós-Graduação em Engenharia de Teleinformática, 2010.

SALES, Gilvandenys Leite, PRESTES, P. A. N., Barroso, G. C., Soares, J. M. Aplicação do Modelo de Avaliação Formativa Learning Vector (LV) à Ferramenta Wiki do LMS Moodle. RENOTE. Revista Novas Tecnologias na Educação. , v.9, p.1 - 10, 2011. 
SALES, Gilvandenys Leite, Leite, E. A. M., RIBEIRO, C. Gerenciamento da Aprendizagem, Evasão em EaD Online e Possíveis Soluções: Um Estudo de Caso no IFCE. RENOTE. Revista Novas Tecnologias na Educação, v.2, p.1 - 10, 2012.

SANTAELLA, Lúcia. O novo estatuto do texto nos ambientes de hipermídia. In: SIGNORINI, Inês. (org.) [Re]discutir texto, gênero e discurso. São Paulo: Parábola Editorial, 2008.p.47-72

SCHLEMMER, Eliane. Metodologias para educação a distância no contexto da formação de comunidades virtuais de aprendizagem. In: BARBOSA, Rommel Melgaço (Org). Ambientes virtuais de aprendizagem. Porto Alegre: Artmed Editora, 2005. p. 29-49.

VALENTE, J. A. Educação a Distância: uma oportunidade para mudança no ensino. In: MAIA, C. (Org.). ead.br: educação à distância no Brasil na era da internet. São Paulo: Anhembi Morumbi, 2000. p. 97-122. 